\title{
Atol das Rocas, Atlântico Sul Equatorial: considerações sobre a classificação do recife biogênico
}

\author{
Marcelo de Oliveira Soares ${ }^{1,2}$, Valesca Brasil Lemos ${ }^{3}$ \& Ruy Kenji Papa de Kikuchi ${ }^{4}$
}

\begin{abstract}
Resumo O Atol das Rocas é considerado o único atol do Atlântico Sul Equatorial e um dos menores do mundo. Devido ao fato de não possuir corais como principais bioconstrutores e ter características morfológicas diferenciadas em relação a recifes do Caribe e Indo-Pacífico sua classificação como Atol pode ser considerada polêmica ao longo do século XX. Análises de campo e de fotografias aéreas foram realizadas para investigar as características do recife biogênico e discutir a classificação como Atol. Os resultados demonstram que existe uma série de características que confirmam a classificação na categoria de Atol e o assemelha a outros recifes de morfologia similar como forma elipsóide, desenvolvimento sobre montes vulcânicos, ilhas arenosas e maior largura do anel recifal a sotavento. Características diferenciadas incluem o anel recifal constituído predominantemente por algas calcárias, foraminíferos e gastrópodes vermetídeos; a laguna com profundidade máxima de $6 \mathrm{~m}$ e restrita a uma pequena porção do recife; a presença de calcarenito em uma das ilhas e a presença de prováveis resíduos recifais (denominadas "rocas") derivados de oscilações eustáticas no Neógeno.
\end{abstract}

Palavras-chave: classificação, atol, rocas, recifes.

\begin{abstract}
Rocas Atoll, Equatorial South Atlantic: considerations about the classification of biogenic reef. The Rocas Atoll is considered the only atoll in the Equatorial South Atlantic and one of the lowest in the world. Due to not have corals as major bioconstructors and have morphological differences from the Caribbean and Indo-Pacific reefs their classification as Atoll as may be considered controversial during the twentieth century. Field analysis and Aerial photographs were taken to investigate the characteristics of the biogenic reef and discuss the classification as Atoll. The results show that there are a number of characteristics that confirm the classification in the category of Atoll and similar to other reefs of same morphology as ellipsoid form, development in volcanic mountains, sand cays and greater width of the ring reef on the leeward. Differentiated features include ring reef consisting predominantly of calcareous algae, foraminifera and vermetid gastropods; lagoon with a maximum depth of $6 \mathrm{~m}$ and restricted to a small portion of the reef, the presence of calcarenite on one of the islands and the probably presence of reef residues (called "rocas") derived from eustatic fluctuations in the Neogene.
\end{abstract}

Keywords: classification, atoll, rocas, reefs.

INTRODUÇÃO Desde os trabalhos geológicos de Darwin (1842), Dana (1853), Daly (1910), Davis (1920 e 1928), a morfologia clássica de um atol em formato circular com a presença de pequenas ilhas ao redor de uma laguna central se transformou em um relevo padrão nos trabalhos de geologia. Barry et al. (2007) comentam que os atóis são recifes oceânicos que possuem um aspecto anular, onde comumente se encontra uma laguna interna e ilhas formadas por depósitos arenosos inconsolidados do Holoceno.

Considerando a evolução dos atóis baseada nos efeitos eustáticos e hidro-isostáticos do nível do mar, observou-se que essa configuração é apenas um estágio temporário que existiu em uma pequena fração de tem- po durante o Quaternário. Assim, a morfologia clássica dos atóis atuais, um conceito bastante reconhecido no meio científico, só passou a ter essa configuração no Quaternário tardio. Os atóis recentes existem em diferentes províncias geológicas dos mares tropicais. Tais ambientes recifais comumente diferem significativamente em relação ao número, tamanho, continuidade e morfologia das ilhas (Dickinson 2004).

A teoria geológica mais famosa para a formação dos atóis é de Darwin (1842). Para este autor é necessário que um monte vulcânico sofra um rebaixamento em relação ao nível do mar e possua um crescimento coralíneo concomitante à subsidência. Estes ambientes são recifes de mar aberto, incluídos aqueles que se de-

1 - Universidade Federal do Rio Grande do Sul, Instituto de Geociências, Departamento de Paleontologia e Estratigrafia, Porto Alegre (RS), Brasil.

2 - Universidade Federal do Piauí, Centro de Ciências da Natureza, Departamento de Ciências Naturais e Arqueologia, Teresina (PI), Brasil.

E-mail:bio_marcelo@yahoo.com.br

3 - Universidade Federal do Rio Grande do Sul, Instituto de Geociências, Departamento de Paleontologia e Estratigrafia, Porto Alegre (RS),

Brasil.E-mail: valesca.lemos@ufrgs.br

4 - Universidade Federal da Bahia, Instituto de Geociências, Laboratório de Recifes de Corais, Salvador (BA), Brasil.

E-mail: kikuchi@ufba.br 
senvolvem na plataforma externa. Uma característica bastante comum é a presença de uma laguna de 30 a 80 metros de profundidade em muitos recifes. A profundidade é provavelmente dependente do diâmetro do atol. No caso ideal a laguna está totalmente rodeada de uma coroa recifal. À exceção dos atóis bem pequenos, que somente possuem centenas de metros ou poucos quilômetros e que, excepcionalmente, podem estar totalmente fechados, as lagunas dos atóis se comunicam com o oceano através de canais (Purdy \& Winterer 2006).

$\mathrm{Na}$ história geológica recente observam-se 425 atóis. Desses, 27 estão localizados no Oceano Atlântico, sendo 26 situados no mar do Caribe. O único atol do Atlântico Sul está situado na costa do Brasil: Atol das Rocas (Kikuchi 1994).

O Atol das Rocas foi descoberto em 1503 devido ao naufrágio da nau de Gonçalo Coelho. A primeira menção por um naturalista ocorreu no final do século XIX, em 1880, por Jean de Léry, que fez uma breve e muito tênue descrição à distância do Atol, quando passava pelas suas cercanias no retorno à França de sua viagem ao Brasil (Vallaux 1940). Apenas com Andrade (1959) Rocas recebe sua primeira descrição científica mais aprofundada, apesar de baseada numa estadia de apenas um dia no Atol. Ele descreveu a morfologia do platô recifal, da laguna, de algumas piscinas, os cálices remanescentes e o arenito de praia em uma das ilhas.

Há várias décadas são realizadas pesquisas científicas no único Atol do Atlântico Sul Equatorial Ocidental, entretanto uma série de aspectos de sua classificação necessita ser mais bem elucidado. A classificação do Atol é considerada polêmica e foram realizadas várias classificações por diversos autores no século XX (Vallaux 1940, Andrade 1959, Ottman 1963, Kikuchi 1994, Kikuchi \& Leão 1997, Gherardi \& Bosence 1999). Assim, este trabalho tem por objetivo contribuir para a classificação do recife biogênico de Rocas, Atlântico Sul Equatorial.

\section{MATERIAIS E MÉTODOS}

Área de estudo O Atol das Rocas está localizado no topo de uma cadeia de montanhas submarinas no Oceano Atlântico Sul, cuja base encontra-se a 4000 m de profundidade no leito oceânico, a $3^{\circ} 51^{\prime}$ 'S Latitude e $33^{\circ} 49^{\prime} \mathrm{W}$ Longitude, distante $266 \mathrm{~km}$ da cidade de Natal e $150 \mathrm{~km}$, a oeste, do arquipélago de Fernando de Noronha, no Nordeste Brasileiro (Kikuchi \& Leão 1997, Gherardi \& Bosence 2005).

O crescimento recifal do Atol ocorreu sobre uma base vulcânica situada em um alinhamento de montes submarinos que consistiriam numa ramificação da dorsal meso-oceânica. Damuth \& Palma (1979) e Gorini (1981) abordaram a morfologia desse alinhamento de montes submarinos, que o próprio Gorini (1981) nomeia como Zona de Fratura de Fernando de Noronha.

Os ventos de leste e sudeste são predominantes ao longo do ano com uma freqüência de $45 \%$ e velocidades variando entre 6,0 a $10,0 \mathrm{~m} / \mathrm{s}$. Estes parâmetros possuem relativa sazonalidade: nos meses de inverno (de junho a agosto), observa-se $35 \%$ para ventos de SE e $15 \%$ para $\mathrm{E}$, com velocidades variando entre 11,0 e $15,0 \mathrm{~m} / \mathrm{s}$; para o verão (de dezembro a abril), a freqüência fica em torno de $20 \%$ para os ventos SE e E, com velocidade freqüentemente acima de 20,0 m/s (Kikuchi \& Leão 1997).

A temperatura da água do mar possui média de $27^{\circ} \mathrm{C}$, podendo chegar a $42^{\circ} \mathrm{C}$ nas piscinas, com salinidade na superfície variando entre 36 e 37 . O regime de mesomarés é semidiurno, com uma variação máxima de $2,7 \mathrm{~m}$, deixando exposto o platô recifal em maré de sizígia baixa (Gherardi \& Bosence 1999).

Trabalhos de campo e laboratório Os trabalhos de campo foram realizados na REBIO (Reserva Biológica) Atol das Rocas durante o período de 30 de janeiro a 25 de fevereiro de 2008. O tratamento do aspecto geral do Atol das Rocas requereu diferentes etapas como interpretação de imagens aéreas, confecção de mapas geológicos da área e visualização "in situ" das características morfológicas que auxiliam na classificação do recife.

As observações do recife foram efetuadas durante caminhadas no topo do recife, exposto nas marés baixas, e durante mergulhos, em apnéia e autônomo, nas partes submersas. Neste segundo deslocamento, utilizou-se um bote inflável. Os pontos de observação foram inicialmente plotados no mapa publicado por Kikuchi (1994) e georeferenciados. Esses dados foram completados com documentação fotográfica detalhada e com amostragens geológicas da estrutura recifal.

As observações foram feitas principalmente com equipamento de respiração autônoma "SCUBA" e também em apnéia ou "snorkeling". Os dados foram registrados a lápis em placas de PVC branco quando referentes a dados subaquáticos. Na parte aérea foram realizados mapeamentos e perfis geológicos utilizando GPS. Uma ampla revisão bibliográfica foi realizada para discutir a classificação do considerado único Atol do Atlântico Sul Equatorial.

RESULTADOS E DISCUSSÕES O Atol das Rocas apresenta em fotografias aéreas uma estrutura geométrica de elipsóide, praticamente circular no seu eixo maior E-W com aproximadamente $3,7 \mathrm{~km}$, sendo o menor eixo na disposição georeferenciada $\mathrm{N}-\mathrm{S}$ com $2,5 \mathrm{~km}$. Os canais, que conectam o interior do recife ao oceano adjacente, estão dispostos nas porções $\mathrm{N}$ e NW. Pode-se observar a presença de ilhas arenosas resultantes de acumulação sedimentar a sotavento e uma laguna restrita a uma pequena porção do recife (NE), não situando-se na porção central. A parte central do recife é dominada por uma areia carbonática biogênica resultante dos processos denudacionais no recife sendo classificado como depósito arenoso intermareal (Fig. 1).

O Recife biogênico de Rocas pode ser considerado um Atol oceânico pelas seguintes características: possui uma plataforma elíptica a circular; tem um anel recifal bem constituído com algas calcárias (Fig. 2A); desenvolveu-se no topo de montes vulcânicos submersos cuja base encontra-se a mais de $4000 \mathrm{~m}$ de profundidade no assoalho oceânico; possui uma laguna rasa (Fig. 2C) e ilhas arenosas no lado do platô recifal (Figs. 


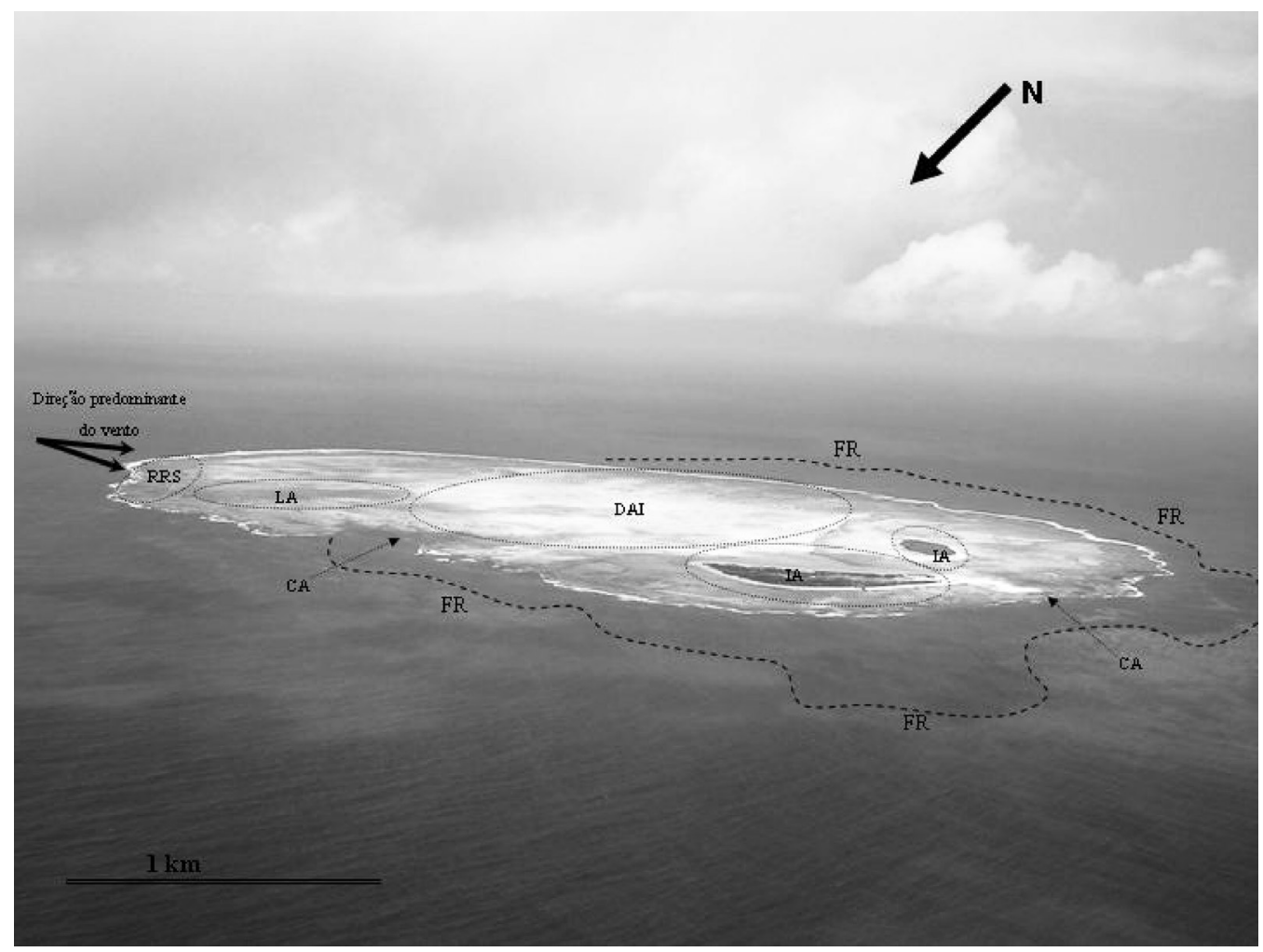

Figura 1 - Zonas geomorfológicas do Atol das Rocas (Atlântico Sul Equatorial) mostrando a forma elíptica, os canais (CA), a Frente Recifal (FR), ilhas arenosas (IA), Depósito arenoso intermarés (DAÍ), Laguna (LA), Resíduos de Recifes (RRS) e a direção predominante do vento que determina as posições a barlavento e sotavento. Imagem modificada a partir de fotografia aérea obtida pela Força Aérea Brasileira (FAB).

2B e 2D) oposto ao que recebe o vento predominante (como nos atóis caribenhos) e uma maior largura do anel recifal na porção barlavento.

Gherardi \& Bosence (1999) diferenciaram características do Atol das Rocas em relação aos recifes do Caribe e Indo-Pacífico tais como: não possuir corais como principais bioconstrutores e uma laguna de baixa profundidade estando restrita a uma pequena porção da área recifal.

Dickinson (2004) aborda que os estudos dos efeitos eustáticos e hidro-isostáticos realizados nos níveis do mar do Quaternário tardio no Oceano Pacífico Tropical indicam que a configuração moderna dos atóis como um recife anular emergente é uma morfologia transitória que não se desenvolveu até o Holoceno tardio na Era Cenozóica.

Segundo a teoria de Darwin (1842), a origem dos atóis seria: "um abaixamento geológico e lento de uma ilha na qual em volta houveram recifes em franjas e com o crescimento dos corais formaria o atol". De acordo com esse conceito clássico, o Atol das rocas não é considerado um verdadeiro atol devido a sua base de formação não ser de corais, e sim predominantemente de algas calcárias. Algumas características deste Atol fogem do padrão de outros atóis no mundo, tal como a laguna que na baixa-mar não chega a ocupar todo o interior do anel coralino. Na baixa-mar, a laguna fica reduzida a um corpo d'água onde a profundidade não passa de 3 metros. Considerando essa característica, Rocas é um atol incompleto, ou se admite que é um atol em evolução e muito recentemente formado. As lagunas dos Atóis do Pacífico possuem grandes profundidades $(>10 \mathrm{~m})$, independente da dinâmica das marés (Vallaux 1940).

Charles Darwin durante sua famosa viagem a bordo do Beagle (1831-1836) elaborou a teoria dos recifes de coral, incluindo aspectos da gênese dos atóis. Desde o trabalho de Darwin, em 1842, até a década de 40 do século passado, persistiram duas correntes a respeito da evolução dos recifes biogênicos: I) aquelas teorias que postulam a necessidade das variações eustáticas com relação ao substrato do recife, para que ele possa se desenvolver e II) aquelas para as quais não há necessidade dessa mudança no nível marinho.

O Grupo 1 inclui a Teoria da subsidência (Darwin 1842): "primitivo recife-barreira anular, que verticalmente cresceu à medida que suas fundações se rebaixavam de maneira contínua ou intermitente" e a Teoria do controle da glaciação (proposta por Daly 1910) enfatiza que o fenômeno da glaciação pleistocênica seria responsável pela formação e arrasamento dos recifes pela exposição subaérea, provocando dissolução na construção e amoldamento da geomorfologia recifal.

No Grupo 2 encontra-se a teoria da plataforma 

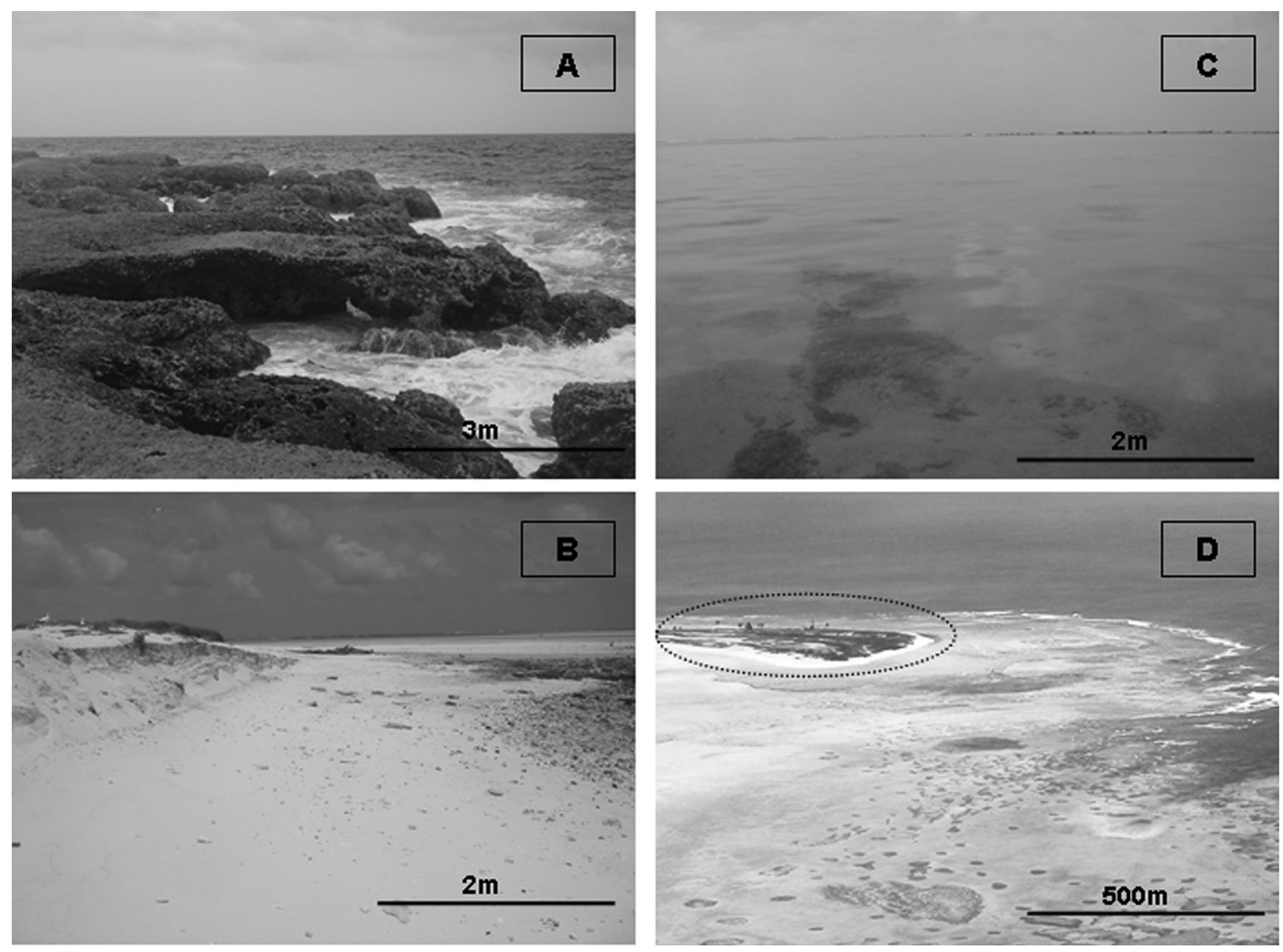

Figura 2 - Feições morfológicas do Atol das Rocas que auxiliam na classificação do ambiente recifal. Figura 2A. Anel recifal bioconstruido por algas calcárias. Figura 2B. Visão da Ilha do Cemitério a Barlavento. Figura 2C. Visão da laguna rasa que se forma a NE no Recife onde se observa os sedimentos do fundo e parte de um recife em mancha ("patch reef"). Figura 2D. Foto aérea da Ilha do Farol (marcada pela elipse) mostrando a parte interna escura que representa a vegetação terrestre.

antecedente (proposta por Hoffmeister \& Ladd 1944) que propõe que numa superfície localizada em profundidade adequada, dentro da zona de crescimento dos recifes, caso as condições ecológicas permitam, recifes se desenvolverão até a superfície do mar, sem que ocorra eustasia.

Toda litosfera oceânica está sujeita ao mecanismo de subsidência térmica, à medida que se afasta das cordilheiras meso-oceânicas (Allen \& Allen 1990) e foi esse o mecanismo segundo o qual cresceram os atóis do Pacífico (Scoffin \& Dixon 1983).

Considerando aspectos genéticos para classificação do recife a ocorrência de subsidência no Atol das Rocas foi comentada por diferentes autores. Andrade (1959) e Ottman (1963) sugeriram em seus estudos geológicos a provável ausência de subsidência no substrato de Rocas. Porém, Kikuchi (1994) argumenta após estudos sísmicos e de testemunhos, que é admissível uma subsidência à taxa de $0,19 \mathrm{~mm} /$ ano desde pelo menos $120 \mathrm{ka}$ AP.

Os blocos residuais do recife no setor à barlaven- to da superfície do Atol das Rocas (Figs. 3A, 3B e 3C) e a existência do calcarenito de praia na ilha do Cemitério (Fig. 3D) não são elementos característicos de Atóis que invalidariam a classificação de Rocas como Atol, como afirmaram Andrade (1959) e depois Ottman (1963), em apoio às idéias de Vallaux (1940). Entretanto, no trabalho de Stoddart (1969) observa-se que tais características não são diagnósticas ao se adotar uma classificação morfológica, sendo as características-chave: a forma do recife, a presença de laguna, as ilhas a sotavento e o desenvolvimento sobre montes vulcânicos.

Darwin (1842) abordou que não existiam atóis verdadeiros no Oceano Atlântico. Davis (1928) classificou Rocas como "a slightly emerged bank atoll, the only one of this kind in the open Atlantic". Vallaux (1940) atribuiu a categoria de "almost-atoll" devido classificálo como um recife-barreira anular e sua laguna ocupar uma pequena área. Kikuchi (1994) e Gherardi \& Bosence (2005) classificaram o recife biogênico como o único Atol do Atlântico Sul Equatorial. 

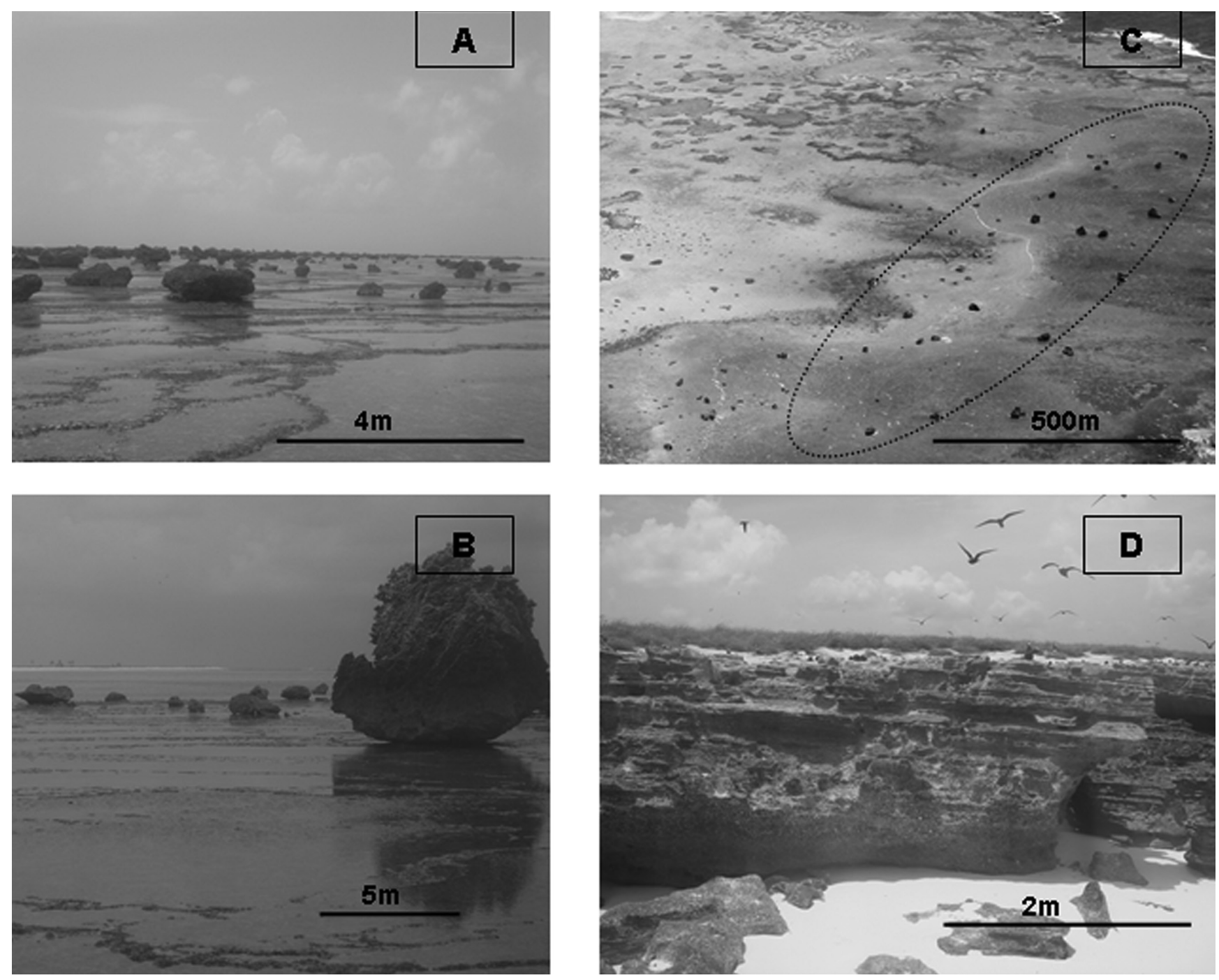

Figura 3 - Elementos geomorfológicos que invalidariam a classificação como Atol oceânico do ambiente recifal de Rocas, segundo autores citados no texto. Figura 3 A. Resíduos recifais dispostos no lado à barlavento do recife. Figura 3B. Foto mostrando o maior dos blocos recifais que ocorrem na área. Foto obtida em maré baixa. Figura 3C. Zona de ocorrência das "Rocas" (resíduos de recife) no setor à barlavento (marcadas pela elipse). Figura 3D. Calcarenito (beach rock) ocorrente na ilha do Cemitério à barlavento.

CONCLUSÕES O problema da classificação do Atol das Rocas decorre da disputa entre um critério morfológico versus genético. Outra questão é o fato das principais teorias de formação e de classificação de recifes coralíneos serem baseadas em recifes do Indo-Pacífico e só mais recentemente no Atlântico, principalmente no Caribe. A elaboração de um sistema de classificação genética para o Atol das Rocas é de difícil execução devido sua formação e crescimento ser resultante de um fenômeno multivariado de eustasia, subsidência, batimetria e crescimento dos bioconstrutores, o que dificulta a integração dos dados. Os critérios morfológicos são aplicáveis de maneira prática e permitem a classificação do recife biogênico de Rocas como um Atol verdadeiro.

Agradecimentos $\mathrm{O}$ presente artigo faz parte da tese de doutorado do Programa de Pós-Graduação em Geo- ciências (UFRGS) intitulada "Geobiologia do Atol das Rocas, Atlântico Sul”. M.O Soares agradece ao CNPq (Conselho Nacional de Pesquisa e Desenvolvimento Cientifíco) pela concessão de bolsa de Doutorado. A PETROBRAS e Fundação SOS Mata Atlântica pelo financiamento da pesquisa dos trabalhos de campo. A Força Aérea Brasileira (FAB) pela obtenção de imagens aéreas do único Atol do Atlântico Sul. Ao ICMBIO (Instituto Chico Mendes de Conservação da Biodiversidade) pela concessão de licença de pesquisa (número 12228-1) e apoio nas atividades de campo (principalmente a Maurizélia Brito, coordenadora da Reserva Biológica Atol das Rocas). Ao Biólogo Carlos Augusto Oliveira Meirelles pelo auxílio na coleta e fotografias subaquáticas. Aos revisores anônimos pelas valiosas considerações. 


\section{Referências}

Allen P.A. \& Allen J.R. 1990. Basin analysis - Principles and Applications. Blackwell Scientific Publications, $451 \mathrm{p}$.

Andrade G.O. 1959. O recife anular das Rocas (Um registro das recentes variações eustáticas no Atlântico equatorial). Anais da Associação dos Geógrafos Brasileiros, 12:29-61.

Barry S.J., Cowell P.J., Woodroffe C.D. 2007. A morphodinamic model of reef-island development on atolls. Sedimentary Geology, 197:47-63.

Daly R.A. 1910. Pleistocene glaciation and the coral reef problem. Am. J. Sci [Ser 4], 30:297-308.

Damuth J.E. \& Palma J.C. 1979. Geomorfologia do fundo atlântico equatorial oeste. In: Chaves H.A.F (ed). Geomorfologia da Margem continental Brasileira e das áreas oceânicas adjacentes. Rio de Janeiro, Série Projeto REMAC n ${ }^{\circ}$, p. p3-88.

Dana J.D. 1853. On Coral Reefs and Islands. Putnam, 300p.

Darwin C. 1842. The structure and Distribution of Coral reefs. Smith Elder, 256p.

Davis W.M. 1920. The small islands of almost-atolls. Nature, 105: 292-293.

Davis W.M. 1928. The coral reef problem. Am. Geogr. Soc. Spec. Pap., 9:1-596.

Dickinson W.R. 2004. Impacts of eustasy and hidro-isostasy on the evolution and landforms of Pacific atolls. Palaeogeography, Palaeoclimatology, Palaeoecology, 213:251-269.

Gherardi D.F.M. \& Bosence D.W.J. 1999. Modeling of the ecological succession of encrusting organisms in recent coralline-algal frameworks from Atol das Rocas, Brazil. Palaios., 14:145-158.

Gherardi D.F.M. \& Bosence D.W.J. 2005. Late Holocene Reef growth and relative sea-level changes in Atol das Rocas, equatorial South Atlantic. Coral Reefs., 24:264-
272.

Gorini M.A. 1981. The tectonic fabric of the Equatorial Atlantic and adjoining continental margins: Gulf of Guinea to Northeastern of Brazil. In: Asmus H.E (ed.) Estruturas e tectonismo da margem continental brasileira e suas implicações nos processos sedimentares e na avaliação do potencial de recursos minerais. Rio de Janeiro, Série Projeto REMAC n 9, p. 11-116.

Hoffmeister J.E. \& Ladd H.S. 1944. The antecedent platform theory. J Geol., 52:388-402

Kikuchi R.K.P. 1994. Geomorfologia, Estratigrafia e Sedimentologia do Atol das Rocas (REBIO-IBAMA/RN). Dissertação de Mestrado, Instituto de Geociências, Universidade Federal da Bahia, 144p.

Kikuchi R.K.P. \& Leão Z.M.A.N. 1997. Rocas (Southwestern Equatorial Atlantic, Brazil): an atoll built primarily by coralline algae. In: Int. Coral Reef Symposium, $8^{\text {th }}$, Panamá, Proc., v.1, 736p.

Ottman F. 1963. "L'atol das Rocas" dans l'Atlantique sud tropical. Revue de Géographie Physique et de Géologie Dinamique., 2:101-107.

Purdy E.G. \& Winterer E.L. 2006. Contradicting Barrier Reef relationships for Darwin's evolution of reef types. Int. J. Earth. Sci (Geol Rundsch)., 95:143-167.

Scoffin T.P. \& Dixon J.E. 1983. The distribution and structure of coral reefs: one hundred years since Darwin. Biological Journal of the Linnean Society., 20:11-38.

Stoddart D.R. 1969. Ecology and morphology of recent coral reefs. Biological Reviews., 20:433-498.

Vallaux C. 1940. La formation atollienne de Rocas (Brésil). Bulletin de L'Institut Océanographique., 37:1-8.

Manuscrito ID 13342

Submetido em 26 de janeiro de 2009 Aceito em 18 de junho de 2009 